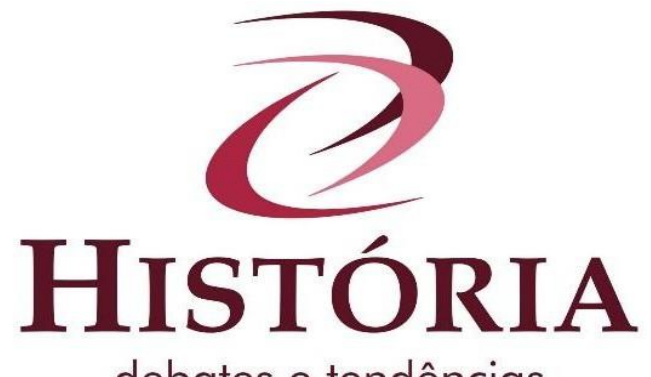

\title{
A identificação do louco e da loucura em Goiás na segunda metade do século XIX
}

\author{
The identification of the mad and madness in Goiás in the second half of the \\ $19^{\text {th }}$ century
}

\section{La identificación del loco y de la locura en Goiás en la segunda mitad del siglo XXI}

Leicy Francisca da Silva ${ }^{\mathrm{i}}$

Resumo: O objetivo central deste artigo é observar o processo de constituição do louco e da loucura em Goiás na segunda metade do século XIX. Procura compreender os debates elaborados em torno do problema, os discursos construídos e, por fim, a definição do lugar para os sofredores de enfermidade mental na província/estado. O percurso metodológico percorrido foi a interpretação dos textos jornalísticos e dos relatórios dos administradores, buscando observar como nestas fontes o sofrimento mental é conceituado, como são classificados aqueles que o sofrem e quais as discussões sobre o modo e espaço para tratálos? Ressaltamos que a busca pela loucura e pelo louco, no período em análise, encaminha, na maioria das vezes, para as páginas policiais, onde aparecem no papel de vítimas ou algozes. O reconhecimento da loucura neste período ocorre no encontro dos limites da humanidade; situa-se o enfermo em situações de violência, crime, suicídio e abandono.

Palavras-chave: Goiás. História. Loucura.

\begin{abstract}
The primary aim of this article is to observe the process of constitution of the mad and madness in Goiás in the second half of the $19^{\text {th }}$ Century. It seeks to understand the debates conducted about the problem, the constructed discourses and finally, the definition of the place for sufferers of mental illness in the province/state. The methodological path followed was the interpretation of journalistic texts and reports by administrators in an attempt to observe the manner in which these sources conceptualize mental suffering, the way those who suffer from it are classified and the existing discussions regarding the way and the facilities to treat them. It is important to note that the search for madness and the mad during the period under analysis frequently leads to pages of police news, where they appear either as victims or tormentors. The recognition of madness in this period occurs in the encounter of the boundaries of humanity; the mentally ill is placed within situations of violence, crime, suicide and abandonment.
\end{abstract}

Key words: Goiás. History. Madness.

Resumen: El objetivo principal de este artículo es observar el proceso de constitución del loco y de la locura en Goiás en la segunda mitad del siglo XXI. Busca comprender los debates elaborados en torno al problema, los discursos construidos y, finalmente, la definición del lugar para los dolientes de enfermedades mentales en la provincia / en el 
estado. El recorrido metodológico fue la interpretación de los textos periodísticos y de los informes de los administradores, buscando observar cómo en estas fuentes se conceptualiza el sufrimiento mental, cómo se clasifican los que le padecen y cuáles son las discusiones sobre el modo y el espacio para tratarlos. Destacamos que la búsqueda de la locura y del loco, en el período examinado, conduce, en la mayoría de las veces, a las páginas policiales, donde ellos aparecen como víctimas o verdugos. El reconocimiento de la locura en este período ocurre en el encuentro de los límites de la humanidad; se coloca al enfermo en situaciones de violencia, crimen, suicidio y desamparo.

Palabras clave: Goiás. Historia. Locura.

\section{Introdução}

O "Mapa dos Julgamentos proferidos pelo Júri da província de Goiás”, do ano de 1851, apontava dentre os crimes nela cometidos, um caso de homicídio cometido por um indivíduo que "foi absolvido, por ter sido julgado louco". Mais tarde, em 1854, na "Relação dos crimes perpetrados na Província, que chegaram ao conhecimento da Presidência do $1^{\circ}$ de julho de 1853 em diante", consta em nota que "o respetivo Delegado se limitou a participar que os dois últimos homicídios, e os três ferimentos ocorridos em 5 de agosto foram cometidos por um alienado, cujo nome não declara”. Nos dois casos, a condição do louco enquanto expressão de violência e perigo social é exposta nos documentos oficiais da administração, bem como sua absolvição pelo mesmo motivo sanitário. O julgamento transcorre em acordo com o Código Criminal de 1830, que afirmava a impossibilidade de julgamento como criminosos dos "loucos de todo o gênero, salvo se tiverem lúcidos intervalos, e neles cometerem o crime". A absolvição do acusado aponta a questão de para onde teria sido encaminhado, ou se teria permanecido nos espaços comungados pela população? Pois a legislação indicava (em seu artigo 12) que "os loucos que tiverem cometido crimes, serão recolhidos às casas para eles destinadas, ou entregues às suas famílias, como ao juiz parecer mais conveniente". A busca pela loucura e pelo louco em Goiás no século XIX encaminha, na maioria das vezes, para as páginas policiais dos jornais, onde aparecem no papel de vítimas ou algozes.

Antes da constituição dos espaços asilares para encerramento do louco, era possível perceber nos espaços urbanos a convivência daqueles fora dos padrões sociais de normalidade, especialmente os que não eram considerados perigosos ou geradores do risco da desordem (PORTER, 1987, p. 169). É, por isso, difícil a observação da loucura, no período em tela, em um primeiro momento, porque é um fenômeno difuso e localizado na malha social da comunidade. Quando passa a ser percebido e apartado da cena social, o 
louco é excluído dos espaços de sociabilidade urbanos e colocado em espaços marginais.

Pinel, ao elaborar o conhecimento sobre a loucura, o faz a partir do paradigma da História Natural, onde "conhecer é classificar, separar e agrupar os diferentes fenômenos em ordens aproximativas"; desta forma, a loucura, percebida como rompimento com a realidade, expressa por sinais, pode ser classificada e agrupada em "classes, gêneros e espécies, enfim numa nosografia" (AMARANTE, 1996, p. 40).

Em Goiás, o primeiro espaço voltado para assistência aos enfermos data do século XVIII, o Hospital Real Militar, mais tarde Enfermaria Militar, ao qual se soma, adentrando o século XIX, em 1825/26, um novo nosocômio, o Hospital São Pedro de Alcântara. Além destas instituições, a administração pública constitui espaços voltados para o abrigo e afastamento dos doentes de lepra; um primeiro nas circunvizinhanças da capital, um segundo na cidade de Meia Ponte, atualmente Pirenópolis (SILVA, 2016), e, em fins do século XIX, a instalação em espaços alugados e precários do Asilo São Vicente de Paula, cujo prédio é finalizado em 1909 e que atendia aos pobres, idosos e doentes, dentre eles os chamados bobos ou loucos mansos (SOUZA, 2017). Para além deste quadro, no que concerne aos sofredores das enfermidades mentais, não se tem na historiografia a identificação de um espaço específico para seu cuidado; exceto a indicação de um desafio ao historiador da saúde, sugerido por Maria Augusta de Sant'Anna Moraes, que faz alusão ao Hospício de Jerusalém, cuja existência é uma incógnita a ser resolvida (MORAES, 2012, p. 64). Da leitura do cônego Trindade, acreditamos que talvez o Hospício de Jerusalém seja apenas a menção ao convento dos padres franciscanos esmoleres da Terra Santa, estabelecido desde 1731, na cidade de Meia Ponte/Pirenópolis, que era "impropriamente chamado de "hospício"” (TRINDADE, 30 de abr., 1946, p. 4).

No período abordado neste artigo, e relativamente à especificidade goiana em fins do século XIX, observamos que os médicos começam a lidar com esse objeto novo, mas não possuem o monopólio desse campo, por isso, para compreender esse tema, busquei perceber nos discursos jornalísticos produzidos e divulgados como a questão do sofrimento mental é conceituada, como são classificados aqueles que dele sofrem, e quais as discussões sobre o modo e espaço para tratá-los? Em síntese, o objetivo desse trabalho é compreender a partir de que momento se percebe a descontinuidade na observação da loucura, do louco e da indicação da necessidade de constituição de espaço ou instituição específica para seu cuidado em Goiás. O percurso metodológico percorrido foi a interpretação das fontes, um conjunto constituído dos textos jornalísticos, em grande maioria relativos a crimes e situações de violência, somada à observação dos relatórios dos administradores, da análise 
da legislação e da escrita literária.

\section{Os loucos, bobos e malucos no cotidiano da cidade}

O que diferencia e identifica bobos, loucos, malucos? Consideramos que a loucura é um termo que expressa diferentes experiências sociais, temporal e culturalmente situadas, exigindo a problematização das diferentes experiências de vivência desta condição (WADI, 2016, p. 78).

Em 1888, Baggi de Araújo no relatório de sua viagem de prospecção às regiões que margeavam o Rio Araguaia, aponta não ter encontrado "um só bobo e um só papo, e apenas um maluco ou louco manso, numa aldea" (Jornal Goyaz, 17 de fev., de 1888, p. 2). No dicionário escrito pelo goiano Luiz Maria Pinto, de 1832, o bobo e o mentecapto são conceituados: mentecapto adjetiva o indivíduo “que perdeu o juízo", por sua vez, bobo é o “estúpido, chocarreiro, que se finge de bobo" (PINTO, 1932, p. 20 e 89). Oscar Leal acrescenta em Viagens às terras Goyanas que "Boyota" é um "termo usado em Goyaz" para "mentecapto". O termo bobo, normalmente utilizado enquanto adjetivo, ganha uma nova conotação em Goiás, substantivado e subjetivado, para explicar uma condição patogênica. Para melhor compreender o fato cabe a leitura de Tolentino Savio, que explica, em 1912, que algumas gírias "aparecem com significação diferente em Goiás”, marcadamente preconceituosas advindas de elementos socioculturais. Na busca por compreender a linguagem cotidiana, e demonstrando em sua conceituação uma relação para com o grupo que povoava o espaço público e a sua imaginação, explica:

\footnotetext{
O adjectivo bobo empregado como substantivo pode significar um indivíduo aparvalhado e também, figuradamente, um monjolo, ou machina rudimentar de beneficiar os cereais. Na gyria carioca e fluminense, porém, significa - relógio -, de onde se nota certa analogia no modo de figurar as palavras. O monjolo é bobo, porque trabalha noite e dia sem necessidade de maior assistência do dono; do mesmo modo que o relógio trabalha continuamente e se deixa levar, sem protesto, pelos gatunos. (O Planalto, 27 de jul., 1912, p. 2)
}

A analogia proposta por seu raciocínio, a definição criada através da sua associação de ideias, seria a do bobo, como indivíduo aparvalhado, que trabalha "sem necessidade de maior assistência do dono", o que "se deixa levar sem protesto"!? Em suma, apresenta o bobo como serviçal. Em 1914, a condição de indivíduo que recebe uma função sem contestação ou reclame foi motivo de propaganda da farmácia local "Bobo, corre a Bom Jesus [farmácia] e compre um frasco de magnésia fluida" demanda o sujeito da campanha 
publicitária sendo de pronto atendido (O planalto, 30 out., 1914, p. 3).

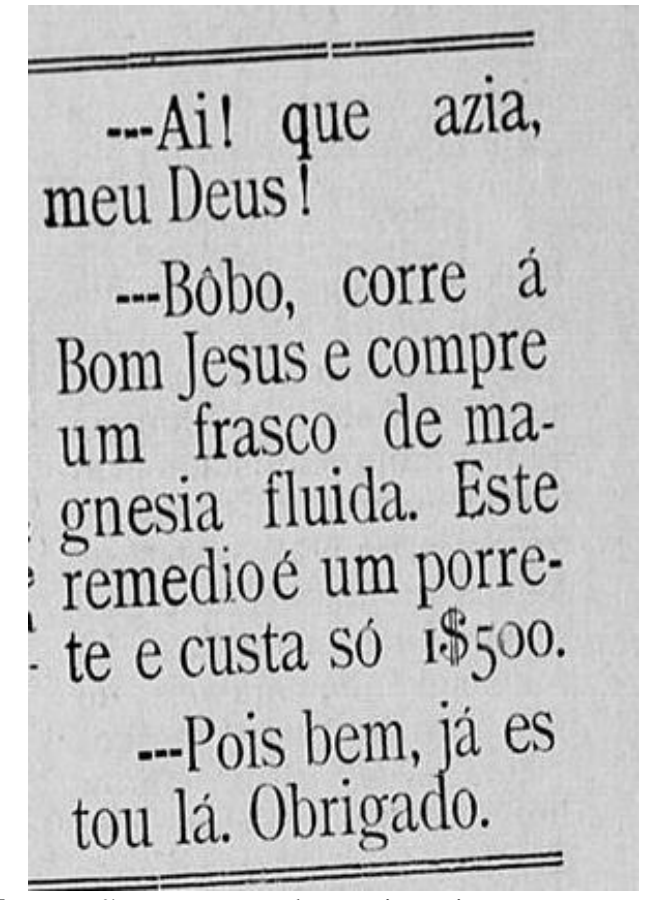

Ilustração: Propaganda nos jornais.

Fonte: O Planalto, 30 de out., 1914, p. 3.

Marilúcia Meireles aponta a existência de número considerável de bobos na cidade de Goiás, advindos da zona rural em busca de assistência (no hospital São Pedro de Alcântara e asilo São Vicente de Paula) foram "adotados" por famílias, mantidos e abrigados em troca da prestação de serviços domésticos em um período que a mão de obra escrava precisava ser substituída (2014, p. 22). Fruto do abandono infantil, em decorrência de relações proibidas ou advindas de violência, e em perspectiva médica e social explicados como "prole degradada", pois considerados filhos de pais sifilíticos, ou sofredores do papo/cretinismo (MEIRELES, 2014, p. 236). Foram incluídos no imaginário social da população através dos afazeres da cidade; e de alguma forma encaixados na normalidade coletiva porque não causavam vexame e podiam ser absorvidos nas famílias e no cotidiano urbano (SANTOS, 2020).

As enfermidades que mais afligiam a população goiana no período em análise eram o idiotismo, o bócio e a sífilis ou lues (SALLES, 1999, p. 89), expondo além de justificativa para o amalgama que o problema tem considerável importância regional e não pode ser destacado dos estudos das outras doenças e aspectos sociais. O problema local do bócio e sua relação com o cretinismo, é tratado no artigo O Far-West do Brasil publicado no jornal Goyaz, onde se interpretava o tema a partir de estudo replicado da Revista de Medicina e Farmácia portuguesa. O bócio chamado de "papo de corda", explica, podia "impedir a 
secreção da saliva e tornar o ouvido pouco sensível aos sons", daí a surdez dos atingidos. Explica que Larousse aceitava que um terço dos bociosos produziam o cretinismo, as duas afecções tinham causas comuns, não sendo, no entanto, a mesma moléstia. Em Goiás, o bócio se desenvolvia em torno da idade da puberdade, em jovens "sem higiene, ou miseráveis, afetados ou não de cretinismo" e distingue três graus de cretinismo: os sofredores do primeiro tipo tinham "inteligência abaixo do nível ordinário", com capacidade para aprender um ofício e comunicação; o segundo, os semi-cretinos possuíam "faculdades intelectuais estritamente limitadas às necessidades do corpo" e sem condições para entrever comunicação; já o terceiro, eram cretinos completos, com total impossibilidade de comunicar-se, tendo "vida vegetativa", eram "infecundos", um grupo "tão raro na província que em mais de oito anos que nela resido só tive ocasião de ver um caso único”. Sobre a relação entre bobo e o cretino explica:

\footnotetext{
Ao indivíduo que em termo chulo chama bobo, denomina a psychiatria de "cretino", palavra que Génin faz derivar de "christianus, christão, porque as pessoas victimas d'essa enfermidade eram consideradas como inocentes e christãs pelos que conviviam com ellas. (...)

Cretino ou bobo é um indivíduo idiota, rachitico, pálido e frequentemente bocioso.

$\mathrm{O}$ dr. Guenot n'uma monografia que escreveu sobre o cretinismo, e que passa por excelente, dividiu duas classes principaes dos cretinos: $1^{\circ}$ os cretinos idiotas; $2^{\circ}$ os cretinos propriamente ditos.

Oito décimos d'esses infelizes são, diz ele, cretinos idiotas; a um corpo bem regularmente desenvolvido, correspondem faculdades intellectuaes e affectivas quase nullas.

A essa classe denominava Esquirol de "idiotas das montanhas".

Há entre eles um grande número de surdos. (...)

Noto nesta província que os bobos, embora sejam de índole colérica e irritável, em circunstancias normaes nem sempre são tristes, pelo contrários as mais das vezes se os vê em quase ininterrupto estado risonho ou sorridente. (10 fev., 1888, p. 1 e 2)
}

Da leitura da fonte a imaginação faz quase perceber um desenho da realidade geográfica da então capital de Goiás, situada às margens da Serra Dourada, e uma necessidade de justificação da existência daquele conjunto populacional, identificado a partir da percepção de sua situação sanitária, e relacionada a condições epidemiológicas locais. Eles foram objeto da poesia dos literatos como Cora Coralina, Marcos Caiado e Victor Ramos de Carvalho, que os imortalizaram em seus versos, inclusive divulgando seus nomes/apelidos. Cora Coralina louva a Maria Grampinho, ou Maria da Purificação, a pobre e livre, era na visão da poetisa uma das "Coisas de Goiás", destas que "que rolam pelo mundo", que "não tem casa nem morada. Vive como quer" (apud MEIRELES, 2014, p. 45). Marcos Caiado sobre "Joana Boba/Joana boa/Joana sempre badulaqueira" acrescenta que 
era também “louca!" (apud MEIRELES, 2014, p. 46). Victor de Carvalho Ramos apresenta reminiscências de sua infância escolar na antiga capital e mostra em seus versos a relação entre os diversos "tipos de rua" daquele cotidiano urbano e os jovens estudantes do Liceu. Em seus escritos os nomes masculinos aparecem com suas manias: Mané boi, Bola-no-ar, Bento, Jacinté-pas e Chibiu, vítimas da violência cotidiana e motivo de riso e gozo de seus opressores.

(...) Defronte do liceu (...) os fujões das aulas de aritmética.

As vezes por ali, arrastando os frangalhos da roupa, Mané boi passava sorrateiro.

E o grupo uma voz ferina sibilava: Boi curraleiro! Mané bobó!

Ele, fechando os punhos, retrucava: É tua avó!

E ao palavrório porco ajuntava as pedradas.

A gente atrás do tronco dava boas gargalhadas.

Outros tipos de rua eram vítimas da Turma: Bola-no-ar, Bento, Jacinté-pas.

Dentre todos os mais popular e esquisito era Chibiu.Chibiu, sua gata fugiu!

E êle, quicé na mão, rugia enfurecido: cale essa boca, maldito! Não seja tão atrevido!

A Turma ria, ria de gozo quando, no outro dia, ele passava de algodão no ouvido. (RAMOS, 1938, p. 1).

A mansidão, bondade e resiliência adjetivam aos que sofriam daquele conjunto de enfermidade, colocada no quadro das alienações. Objetivados e coisificados, nos espaços e relações sociais, tinham em seu trabalho o modo de aceitação nas famílias e apareciam nos escritos como vítimas da violência cotidiana.

\section{O louco violento, ou como o problema da ordem social e moral é colocada nos discursos.}

O segundo grupo caracterizador da loucura em Goiás é aquele dos loucos cuja presença desorganizava a ordem social e moral. Este sujeito é percebido como selvagem, primitivo e sua humanidade não é reconhecida (SANTOS, 2020). Para eles, os asilos e seu pessoal religioso, como no São Vicente de Paula, não estavam preparados; também a cadeia não era a instituição indicada por gerar risco aos outros presos e a sua própria vida, e nas ruas causavam temor. Nesse aspecto, parece elucidativa a avaliação de Danilo Rabelo, que ao tratar do processo de intervenção sobre os comportamentos na cidade de Goiás, aponta que, desde 1828, percebia-se, inclusive na legislação, uma preocupação com a relação entre os loucos e o espaço urbano, porque eles eram considerados os responsáveis por perturbarem a ordem e a moral pública. O Regimento das Câmaras de 1828 (Título III, lei de $1^{\circ}$ de outubro, no art. 66) apontava a necessidade de "cautela contra o perigo proveniente da divagação de loucos, embriagados" e ainda com "animaes ferozes, ou damnados, e 
daquelles, que correndo, podem incommodar os habitantes" (RABELO, 1997, p. 70). Do viver em condição de loucura nas notas de jornais, observa-se a falta do cuidado e atenção específica exigida pela condição patológica, pois pouco aparece como preocupação do campo médico, era da justiça que advinham os informes sobre o cotidiano deste grupo específico. No entanto, se a legislação os colocava no mesmo patamar de animais ferozes, os dados observados os expõem na condição de padecedores mais que de executores da violência. O delegado de polícia da cidade de Formosa da Imperatriz informava, em 1879, "haver sido encontrado no dia 6 dentro de um córrego da fazenda denominada roteador, 3 léguas de distância da mesma cidade, o cadáver do alienado Antônio de Castro". Naquele caso, a autoridade policial determina a expedição de "ordem para a captura e processo do indiciado", indicando ter sido vítima de assassinato (Correio oficial 4/01/1879 p. 2).

Quase sempre tratando dos espaços da loucura e consequentemente do louco aludimos a prisão da capital. Ali indivíduos como o "mendigo, mentecapto e cego" Themoteo, "que vivia vagando pelas ruas sem recursos" eram recolhidos, alimentados "pela verba concedida aos presos indigentes" e colocados à disposição do juiz e da polícia. (Correio Oficial, 23 de jun., de 1882, p. 1). Fora da capital, era ainda a cadeia, o espaço que absorvia os indivíduos que destoavam da norma moral e comportamental exigida nos espaços urbanos. Em Arraias, o subdelegado, ao recolher à prisão ao alienado Dionísio José dos Santos, cobrava da tesouraria os gastos com roupas que cobrissem a nudez que ele expunha publicamente (Correio oficial. Goiás, 27 de fev., 1869, p. 2). Na falta da cadeia, o ajuste era feito para transferência, como fez o Juiz de direito da comarca do Rio Paranã, que informava do acordão relativo a prisão na cadeia da capital do alienado Eustáquio Januário (Correio Oficial 24/10/1877, p. 3). Esses procedimentos que se repetem, mostram o desacordo entre a legislação criminal do período que impedia a criminalização e a punição de crimes cometidos por indivíduos alienados de um lado; e de outro a prática que os encaminhava, na falta de espaços próprios, ao encarceramento quando eram considerados incômodos. Eram muitas vezes sujeitos e vidas vitimadas pelo abandono como no caso do escravo Francisco, filho de Ana, que no momento da partilha cabia a Joaquim Luiz Brandão, que "não quis ficar com ele porque era mentecapto por isso ficou com a mãe (...) mas esta não chegou a ir com ele porque cazou com um carpinteiro chamado Vicente que deu dinheiro pela sua liberdade" (O publicador Goyano, 25 set., 1886, p. 4).

E quanto aos presídios? Laura de Melo e Souza os caracteriza como locais destinados àqueles desclassificados das cidades, inclusive absorvendo os doentes indesejados (1982). O caso do Raymundo Gonçalves de Oliveira nos proporcionam algumas 
pistas, porque em 1883 "soffrendo de alienação mental, havia se embrenhado nas mattas" e "foi devorado, por uma onça", seus restos mortais encontrados em uma roça, no Córrego Azul, nas proximidades do presídio de Santa Maria do Araguaia (Correio Official, 17 de nov., 1883, p. 1). A assombrosa morte indica que aquele espaço pode ter servido para exclusão dos doentes mentais não alcançados pelo asilo, instituição prisional ou pelo Hospital São Pedro de Alcântara. Hipótese relevada pelo conhecimento mais profundo do caso:

\footnotetext{
Morte horrível - Existia no presidio de Santa Maria do Araguaia Raymundo Gonçalves d'Oliveira, que sofrendo de alienação mental, muitas vezes iludia a vigilância das pessoas que dele cuidavão, e internava-se nas mattas, onde com dificuldade era encontrado. Em uma dessas ocasiões, reproduzindo-se tal procedimento, alguns indivíduos sahiram à procura do louco, mas só acharam o seu cadáver que estava em uma roça, sita no córrego Azul, pouco distante do presídio. Pelo exame que o comandante do presidio, mandou proceder à 30 de maio último, ficou constatado que Raymundo fora vítima de uma onça, a qual havia-lhe roído até parte dos ossos! (A Província de Goyaz, 14 de jul., 1883, p. 4)
}

Elucida-se nesta nota a existência no presídio de quem "dele cuidavam" e a quem o comandante podia mandar proceder o "exame". Os presídios eram mais que locais ermos para degredo e proteção das fronteiras, eram espaços para onde famílias inteiras eram enviadas com o objetivo de povoar, ocupar e proteger os limites, em suma constituírem núcleos de povoação. O Presídio do Jurupesen, na década de 1870, estava em plena atividade, crescia e tomava "impulso" quando o administrador da província, Ernesto Augusto Pereira, mandou construir "uma capella e uma enfermaria, edifícios de palpável necessidade", acreditando que "em breve tempo se torne uma importante povoação", pois “tem-se mudado para ali algumas famílias de Pilar e ainda são esperadas outras d'alli, de S. Rita, Mato Grosso, etc.” (J. Alto Araguaya, 15 de fev.,1870, p. 1).

É possível indicar que os presídios como espaços de povoação e exclusão absorviam esses loucos e como alhures sofriam com a carência de médicos e com o isolamento, como atestam as memórias. Explicita Frei Michel Laurent Berthet que em 1882, no norte da província, um cônego de sua Ordem "se ocupa[va] de medicina com sucesso" era "chamado para curar o corpo e a alma" e durante viagem foi requisitado para dar assistência a um ferido numa distância de seis léguas do presídio de Jurupensen (1982, p. 118).

Desclassificado socialmente o louco é excluído para lugares onde se perde em meio a uma massa amorfa constituída por outros caracterizados como anormais. E embora definidos como autores da violência, de atos de desagravo à moral, nos jornais é como 
vítimas desta que eles aparecem na maior parte das vezes. Qualificados como enfermos e, por vezes, situados em espaços não específicos e próprios para os sofredores da patologia, como no caso dos presídios. Nesse processo, se empreende um deslocamento relativamente aos signos de distinção do louco "vê-se ele envolvido numa experiência moral do desatino revestida por outra qualidade" (FOUCAULT, 2009, p. 123) e nesse sentido o que percebe é essa nova consciência da loucura que é alterada, como algo que deveria ser corrigido. Se se percebem loucos no presídio, na cadeia, no hospital, esse deslocamento problemático gera uma confusão na sua indivualização, o louco ao se perder nesse amplo espectro do que poderia ser considerado loucura, permite a reelaboração de uma nova e diferente consciência desse quadro de sofrimento mental.

\section{Suicídio e Loucura}

Em alguns casos, nos jornais goianos os corpos de homens e mulheres em condição de escravidão se apresentam como peça de interesse policial, e ali na informação de suicídio, chama atenção a adição da loucura ou alienação como justificativa explicativa do gesto. José Roberto do Amaral Lapa lembra que um dos modos como os escravos são apreendidos nas memórias, é através da apresentação dos seus corpos, possibilitando perceber sua "condição humana, a anatomia, a mente e a alma entendidos sempre sob a interação da sociedade e cultura em que estão" (2008, p. 207). Se o suicídio de escravos já foi tema corrente na historiografia, a loucura ou perturbações mentais graves, relacionada como justificativa explicativa para estes atos ainda precisa ser mais profundamente analisada (KARASCH, 2001 e OLIVEIRA e ODA 2008).

No "Expediente do dia 21 de maio de 1879", nas notícias relativas a crimes, a polícia afirmava ciência "de que a 16 do mesmo, em um acesso de alienação mental, suicidou-se nesta capital, perfurando o estomago com uma faca, Lourenço, escravo do Conego Manoel José do Coutto Guimarães" (Correio Oficial, 4 de jun., 1879, p. 3). Para a vítima da alienação, a condição de escravidão não dava margem para questionamentos em relação a sua morte, afirmada por senhores e imprensa como suicídio e confirmada nos exames de médicos, deixava de ser preocupação, não merecia inquérito das autoridades policiais, como no caso a seguir:

Suicídio: no dia $1^{\circ}$ de novembro último, o subdelegado de polícia de vila Formosa, fez auto de corpo de delicto no cadáver do escravo Porfírio, pertencente ao cidadão Joaquim Miguel de Oliveira residente no lugar denominado Cedro, à três 
léguas da dita villa, verificando-se ter o mesmo escravo falecido em consequência de uma facada que em si mesmo dera na região do estomago. Pelo inquérito a que se procedeo o dito funcionário ficou averiguado haver o infeliz posto termo a sua existência por motivos de desgostos (Correio Oficial, 23 de dez., 1876, p. 4).

Os desgostos eram, como a alienação mental ou loucura, dados subjetivos decorrentes dos sofrimentos dos cativos, por sua condição, e não havia procedimento de exame que os detectassem; era a autoridade da fala e do saber de outrem que sustentava tal alegação.

O autoextermínio, por suas características, está diretamente relacionado ao impedimento da punição e, de certo modo, a inexistência nos jornais de notícias sobre o homicídio de escravos, ou escravos loucos, chama atenção sobre a hipótese da injustiça e pode, em determinado contexto, deixar entrever nessa lógica que a alusão à condição de alienação apenas reforça a impunidade no caso de existência de crime. A loucura aparece nesse quadro como um agravante e elemento a mais para justificar, possivelmente, condições inexplicáveis da referida morte, como por exemplo facadas no ventre, e talvez retirar do fato, como já abordado por Bastide (1943) e Mattoso (2001) a possibilidade de acusação.

Outro elemento de reforço a essa hipótese é o período em que encontramos esses fatos, as décadas de 1870 e 1880, quando há o fortalecimento dos movimentos abolicionistas, inclusive em Goiás. Talvez seja sintoma da dificuldade ou impotência de uma sociedade branca de impedir as transformações em curso e as novas ordenações das relações entre indivíduos, bem como de aceitá-las, deste modo no processo de moralização social, pesos e medidas diferentes de acordo com o padrão de posição social e de cor eram utilizados (MATOSO, 2001, p. 221 e 222)

A relação entre suicídio e sofrimento mental, ou desgostos e a condição da vítima, define de todo o modo o campo em que o ato era tratado; lembrando Oliveira e Oda, os desgostos provenientes do cativeiro são argumentos clichês nos documentos oficiais (2008, p. 386). Por outro lado, e em consonância com a análise de José Roberto do Amaral Lapa que cobra a consideração da "racionalidade da mente e o exercício da ação/reação defensiva ou letal, para o próprio corpo", e evitando a coisificação, e respeitando que o corpo

\footnotetext{
do escravo tem imanentes sonhos, ideias, emoções e memória, que são usadas em seu favor. Enquanto seu cérebro puder dar ordens ao corpo, resta a esperança de essas ordens contrariarem as do senhor, quando estas o penalizam. O corpo poderá ser assim o derradeiro território da liberdade do escravo (2008, p. 211).
}

Indicamos a possibilidade do uso da loucura como ferramenta de resistência. Em sua maioria, os casos de loucura, ou acesso de loucura, são relacionados a pessoas negras, 
pobres ou em condição de escravidão. Disto advêm interpelações adicionais. Estariam conexas às condições de alimentação, e de doenças decorrentes da carência nutricional, como o beribéri? À violência sofrida? Ou a ambas as condições? Cypriana é um caso que reforça essa preocupação. Ela fica "Oito mezes sem comer!" e mantem-se atuando nos afazeres domésticos (O publicador goyano, 28 de ago., 1886, p. 3).

Suspeitamos ao interrogar as informações jornalísticas, avisados por Revel e Peter, que a palavra, sobre o corpo ou enfermidade, pode ser expressão mentirosa sobre o objeto de que trata, e se de um lado o "doente deveria ser o suporte abstrato de uma entidade nosológica", de outro "ele usa de astúcia e engana o médico" (REVEL E PETER, 1995, p.143 e 145), ou o seu senhor, ou a sociedade inteira, especialmente diante de uma enfermidade irreparável no corpo, como a doença mental. O caso de Cypriana, cuja loucura é naturalizada e aproximada muito facilmente da monstruosidade, pode também ser compreendido sob o signo da esperteza.

\footnotetext{
(...) escrevem da Cachoeira à Gazeta de Notícias: - "Uma preta de nome Cypriana foi, há oito mezes atacada de alienação mental. Desde o dia em que teve o primeiro acesso até hoje - nunca mais tomou insignificante alimentação. Entretanto, essa infeliz, cuja loucura é perfeitamente pacifica, levanta-se todos os dias, anda por dentro de casa e presta mesmo alguns serviços domésticos" $(\mathrm{O}$ publicador goyano, 28 de ago., 1886, p. 3)
}

Cypryana nos faz questionar sobre sua vida, era escrava? Em caso positivo, a disciplina sobre o seu corpo e a cobrança do trabalho poderiam ser amainadas pela loucura mansa. Estariam aí presentes as trapaças, os limites da honestidade, as contestações justificadas na própria opressão da condição de escravidão imposta (MATTOSO, 2001, p. 157). O corpo de Cypriana continuava respondendo às exigências do regime escravista; portanto, sua loucura "perfeitamente pacífica" era apenas um caso excepcional, o uso produtivo do corpo era parcialmente preservado, não exigindo deste modo repressão, mantinha-se dentro das normas da disciplina do trabalho que lhe era imposto.

Pela doença encontramos o seu ausente, o corpo, e para além dele o doente. A enfermidade revela e qualifica na mulher ou "homem que tem fome, trabalha e morre, o suporte abstrato de qualidades gerais" (REVEL E PETER, 1995). Converge no corpo doente, vidas de sujeitos marginalizados. Nestas existências encontramos a astúcia. No caso específico de Cypriana, diante da impossibilidade natural de viver oito meses sem alimentação, se pode notar na loucura um modo de resistência e constituição de condições de vida possível frente as adversidades e desgostos da escravidão.

A afinidade entre suicídio e loucura se repete em outros quatro episódios noticiados 
no século XIX. Primeiro, o caso do religioso Joaquim Theodoro Linhares, ocorrido em 1894, na cidade de Goiás. O padre, formado pelo Seminário Episcopal de Santa Cruz de Goiás, era "exemplo de caridade" a ser imitado (Correio Oficial, 12 de jan. 1877, p. 3 e 22 de fev., 1892, p. 2). Era chefe do Partido Católico local e "distinto e prestigioso amigo e zeloso vigário do Rio Bonito", predicativos que impediam a aceitação do suicídio como explicação de sua morte, mesmo ciente de seu sofrimento e loucura (Estado de Goyaz. 5 de nov. 1892, p. 3).

A saúde mental do pároco é motivo de preocupação, pois havia sofrido um "insulto cerebral", em março de 1894, e o seu desaparecimento ocorre em maio daquele ano, após ser vitimado por "um novo acesso cerebral" (Estado de Goyaz, 11 de março de 1894, p. 3; 2 de jun., 1894, p. 3). Nas páginas do jornal a informação preocupada de que, "o nosso amigo padre Linhares indo a passeio aos arredores da cidade, no dia 29 do passado perdeuse no mato. Várias pessoas estão à sua procura" (idem). Quando o cadáver de Joaquim Theodoro Linhares é encontrado, dez meses após o seu desaparecimento, a notícia é apresentada com detalhes e sentimento de pesar, confirmando que "infelizmente está verificado que faleceu o padre Joaquim Theodoro Linhares",

Tendo sido encontradas as ossadas mais ou menos a meia légua da cidade, para ali se dirigiram o rev. Padre Pedro Ribeiro da Silva, a família e parentes do finado e o sr. Raymundo descobrindo, a alguma distância do rio Rio Vermelho, dentro do matto, os despojos do inditoso sacerdote, os quaes foram conduzidos ao cemitério público. Conquanto o padre Linhares estivesse, na ocasião de seu desaparecimento sofrendo em suas faculdades mentaes, não se pode atribuir sua morte ao suicídio, porque a arma que consigo levara estava à distância e não se encontrou vestígio algum de chumbo no esqueleto. Demais, ele tinha por habito passear às tardes e se divertia a caçar passarinhos. A polícia tomou conhecimento do facto. Foram celebradas Missas pelo descaço do finado. Nossos sentidos pêsames à família. (Estado de Goyaz, 31 de mar., 1895, p. 3)

No caso do clérigo, o suicídio é inaceitável, mesmo diante da condição de alienação mental. Justificativas são colocadas como elemento explicativo, a polícia é avisada, as missas rezadas, o enterro em campo santo - proibido aos suicidas - efetuado. A loucura é posta como explicadora do desaparecimento, e a arma pelo gosto e hábito de caçar passarinhos. O suicídio, mesmo em condição de desespero irracional, não era argumento aceito para um cristão, era submetido a um julgamento moral cruel: "o suicida é sempre ou um doido, ou um tolo, ou um caloteiro, e muitas vezes as três coisas juntas" (O publicador Goyano, 30 de ago., de 1885, p. 3)

O segundo caso, ocorrido em 1889, do também sacerdote Luiz Manoel, residente na cidade Meia Ponte (Pirenópolis), onde o padre, "que sofria das faculdades mentaes 
suicidou-se(...), dando um profundo golpe de navalha no pescoço" (Jornal Goyaz, 28 de jun., 1889, p. 2). Além de ter sido professor de latim e francês da cidade, entre 1869 e 1876 , dados exposto no Relatório apresentado pelo presidente Antero Cícero de Assis $\left(1^{\circ}\right.$ de junho de 1876, p. 2), nada mais consta sobre o religioso e seu ato.

$\mathrm{Na}$ condenação do suicido exposto como desgosto da vida, ato de insensatez, mas nem sempre voluntário: "o louco que se suicida não sabe o que faz" (A tribuna livre, 13 de ago., 1881, p. 2). Para os que em uso de suas faculdades mentais; o trabalho, as aptidões, as virtudes, eram modos de suportar as dificuldades da vida, porque o suicídio era transgressão da lei cristã (idem). Covardes eram considerados os que não se curvavam à lei justa dos desígnios da divina providência (A Cruz, 25 de fev., 1891, p. 292). A análise sobre o suicídio de uma mulher leva ao questionamento sobre “ (...) estaria em seu completo juízo?” (Jornal Goyaz, 20 de fev., 1891, p. 4).

Outros dois casos de suicídio relacionados à loucura são noticiados nos jornais goianos. O do preso Francisco Gomes da Rocha, em 1884, dá pistas das condições de violência cotidiana sofrida por aqueles acometidos de enfermidades mentais e encarcerados: “As 5 do andante, numa das prisões da cadea desta capital onde era contido solitariamente, suicidou-se, por asphyxia o alienado Francisco Gomes da Rocha, atando ao pescoço pedaços da própria camisa, conforme se verificou do competente exame procedido em seu cadáver." (Correio Oficial/Supplemento, 11 de out., 1884, p. 5)

Encarcerado em célula especial e "contido solitariamente", nenhum crime lhe é imputado, a condição de saúde parece ser a única explicação para seu aprisionamento, isso porque os espaços da loucura no século XIX ainda são pouco demarcados, e o seu tratamento e reconhecimento pouco elucidado.

O outro caso, também é apresentado pelo chefe de polícia em 1889,



O caso de Joaquim Bastos, pobre e sofredor de alienação mental não foi objeto de análise médica, o motivo indicado era suficiente para descarte do exame de corpo de delito e da possibilidade de existência de crime. 


\section{Considerações finais:}

Desde a década de 1870, a sensibilidade e o olhar dos administradores da província goiana localizavam, classificavam e individualizavam aqueles sujeitos, demonstrando a preocupação com a constituição de espaço para tratamento e encarceramento. Em 1874, o presidente da Província, Antero Cícero de Assis, explica que havia feito a compra e reparação de um salão e três quartos em uma casa anexa a enfermaria militar para abrigo e cuidado dos alienados (GOIÁS, Relatório... $1^{\circ}$ de jun., 1874, p. A4-1).

Em 1881, foi a vez de Leite de Moraes, presidente da província, lamenta a inexistência de um hospício para alienados na província. Obrigando as autoridades policiais a recolherem na prisão os infelizes alienados (goiás, relatório. 30 nov., 1881, p. 52 e 53). O delegado de polícia lamenta ainda que a cadeia e o Hospital de Caridade - para onde eram encaminhadas as mulheres - não eram a instituições apropriadas para aquele conjunto. Mas que no espaço público representavam ameaça e afronta social (Goiás, 30 nov., 1881, p. 52 e 53).

A especificidade da doença mental era considerada nos relatórios posteriores, onde se insistia na inexistência de estabelecimento na capital "onde possam ser internados os loucos", "infelizes" que continuavam a ser "recolhidos à cadeia", e propunha-se, como solução, que o Estado entrasse em acordo com a Diretoria do Asilo São Vicente de Paula, para que ali fossem internados aqueles doentes, "em pavilhões construídos para esse fim" (Goiás, 15 de nov., 1891, p. 15 e 16). As freiras dominicanas, responsáveis pelo trabalho interno do referido asilo, quando do início de suas atividades apontam a impossibilidade de recebimento do louco, entendido como o furioso ou insano; distinto do quadro formado por bobos, cretinos, idiotas, uma ampla categoria que não se enquadrava no conceito de "doidos varridos nem loucos de rua; tampouco doentes mentais" que seriam recebidos e tratados na instituição (MEIRELES, 2014).

E por fim, como iniciamos este artigo expondo o modo como o Código Criminal do Império dava tratamento específico para os crimes cometidos por indivíduos em condição de alienação, especificidade legal respeitada na década de 1850 pelo Júri da Província Goiana; finalizo expondo que localmente, havia por parte das autoridades públicas o reconhecimento da especificidade da condição dos indivíduos atingidos pela loucura. É o que se percebe pela Resolução número 633, de 30/04/1880, aprovada pela Assembleia Legislativa Provincial e sancionada pelo presidente de província Aristides de Souza Espindola. A citada resolução, em seu artigo único, dispensava "o alienado Manoel 
Sabino" do pagamento de impostos (da décima urbana de 2 casas que possui) "enquanto perdurar o seu estado enfermo" (Correio oficial 19/05/1880, p. 1). Dava, portanto, tratamento legal específico em decorrência de sua condição sanitária. Embora o Código Criminal de 1830 indicasse a impossibilidade de punição do crime cometido por alienados, no cotidiano da ação das autoridades policiais a prisão se transformava em instituição responsável pelos indivíduos que causassem desordem e desassossego no espaço público, o que deve ter sido causado por uma interpretação que considerava os loucos e tipos de rua como desordeiros ou arruaceiros. O Regulamento de 1842 deixava entrever a possibilidade de ações de controle que permitiam a atuação contra indivíduos apontados como responsáveis por desassossego público. Vadios, mendigos, prostitutas, bêbados, turbulentos, ou todos e quaisquer indivíduos que perturbavam a ordem coletiva, fosse "por palavras ou ações que ofendem os bons costumes, tranquilidade pública e a paz das famílias". ii

Enfim, na segunda metade do século XIX em Goiás, a loucura é individualizada. No entanto, do como como percebe Foucault, como "gêmea estranha do crime, pelo menos ligada a ele, por uma vizinhança ainda não posta em questão" (FOUCAULT, 2009, p. 437). Deste modo percebe-se que os mecanismos de poder e as estratégias de intervenção indicavam a disciplina sobre o espaço confuso do internamento; demarcava o lugar para os indivíduos considerados em condição de anormalidade, e utilizando de "métodos de repartição analítica do poder" identificava aqueles que deviam ser excluídos (FOUCAULT, Michel, op. cit., 2000, p. 165.)

\section{Referências Bibliográficas:}

AMARANTE, Paulo Duarte de Carvalho. O homem e a serpente: outras histórias para a loucura e a psiquiatria. - Rio de Janeiro: Editora Fiocruz, 1996, p. 37.

BASTIDE, Roger. Os suicídios em São Paulo, segundo a cor. Boletim de Sociologia da Universidade de São Paulo, São Paulo, USP, n.71, p.1-49. 1943.

BERTHET (frei Michel). Uma viagem de missão pelo interior do Brasil. In Memórias Goianas I. - UCG. Goiânia. Centauro Graf. Ed., 1982.

BUENO, Jerônimo Carvalho. História da medicina em Goiás, 1979.

FOUCAULT, Michel. História da loucura: na idade clássica. - São Paulo: Perspectiva, 2009.

FOUCAULT, Michel. Vigiar e punir: o nascimento da prisão. Petrópolis: Vozes, 2000. 
KARASCH, Mary C. A vida dos escravos no Rio de Janeiro (1805-1850). São Paulo:

Companhia das Letras. 2001.

LAPA, José Roberto do Amaral. Os excluídos: contribuição à história da pobreza no Brasil (1850-1930). Campinas, SP: Ed. Unicamp, 2008.

MATTOSO, Kátia Queiroz. Ser escravo no Brasil. São Paulo: Brasiliense, 2001.

MEIRELES, Marilúcia Melo. Os "bobos em Goiás: enigmas e silêncios. Goiânia; Editora UFG, 2014.

MORAES, Maria Augusta de Sant'Anna. Dos primeiros tempos da saúde pública em Goiás à Faculdade de Medicina, 2012.

OLIVEIRA, Saulo Veiga; ODA, Ana Maria Galdini Raimundo. O suicídio de escravos em São Paulo nas últimas duas décadas da escravidão. História, Ciências, Saúde - Manguinhos, Rio de Janeiro, v.15, n.2, p.371-388, abr.-jun. 2008.

PINTO, Luiz Maria da Silva. Dicionário da Língua Brasileira. - Typographia de Silva, Ouro Preto, 1932, p. 20 e 89.

PORTER, Roy. Uma história social da loucura. Rio de Janeiro: Jorge Zahar E., 1990.

RABELO, Danilo. Os excessos do corpo: a normatização dos comportamentos na Cidade de Goiás, 1822-1889/Danilo Rabelo; Orientadora Olga Rosa Cabrera Garcia. - Goiânia, 1997.

SALLES, Gilka V. F. de. Saúde e doenças em Goiás (1826-1930). In Saúde e doenças em Goiás: a medicina possível - uma contribuição para a história da medicina em Goiás. Lena Castello Branco Ferreira de Freitas (org.) - Goiânia: Ed., da UFG, 1999.

SANTOS, Ronivaldo Oliveira Rego dos. O projeto do Manicômio Adauto Botelho de Goiânia. - São Paulo, Fonte Editorial, 2020.

SILVA, Leicy Francisca da. Eternos órfãos da saúde: medicina, política e construção da lepra em Goiás. Goiânia: Ed., da UFG, 2016.

SOUZA, Rildo Bento de. A lembrança dos esquecidos: o acerco fotográfico dos internos do Asilo São Vicente de Paulo na Cidade de Goiás. In Histórias das doenças: percepções, conhecimentos e práticas. Organização Sônia Maria de Magalhães, Leicy Francisca da Silva, Roseli Martins Tristão Maciel. - São Paulo: Alameda, 2017.

WADI, Yonissa Marmitt. "Eu gostaria que estas cartas fossem tudo num jornal, para todo o povo saber...": a escrita epistolar como fonte para a história da loucura. In Uma história brasileira das doenças. Vol. 6. Organização Sebastião Pimentel Franco, Dilene Raimundo do Nascimento, Anny Jackeline Torres Silveira. - Belo Horizonte, MG: Fino Traço, 2016, p. 73. 
Recebido em 23/07/2020

Aprovado em 02/09/2020

Publicado: 1\%01/2021

\begin{abstract}
${ }^{\text {i }}$ É Bacharel e licenciada (1999), tem mestrado (2003) e doutorado (2013) em História pela Universidade Federal de Goiás. É professora no Departamento de História da Universidade Estadual de Goiás e compõe o quadro permanente do Mestrado Profissional em Ensino de Ciências da mesma universidade.

ii Regulamento ${ }^{\circ} 120$, de 31 de janeiro de 1842, que regulava a execução da parte policial e criminal da lei $\mathrm{n}^{\circ}$ 261 de 3 de dezembro de 1841, deixava entrever a possibilidade de ações do controle social. Na legislação sobre a atribuição do chefe de polícia, ver seu artigo 58, parágrafo $2^{\circ}$. Sobre as funções do Juiz de Paz, observar o artigo 65 , parágrafo $4^{\circ}$.
\end{abstract}

